\title{
LAS ÚLTIMAS APARICIONES \\ de la Virgen en Latinoamérica: una lectura antropológica
}

\author{
FABIÁN SANABRIA \\ Profesor asociado a LA FACULtad DE CIENCIAS humanas Y \\ económicas de la universidad Nacional de Colombia, Medellín \\ sanfabian73@hotmail.com
}

\section{Resumen}

\begin{abstract}
I ICHAS APARICIONES SE PRESENTAN COMO EJEMPLO DE UN PROCESO MÁS LARGO DE "RECOMposiciones del creer en la modernidad", a partir de la reconstrucción etnográfica de un acontecimiento observado en cuatro contextos: Pereira-Colombia-, Cuenca -Ecuador-, San Nicolás -Argentina-, y Betania -Venezuela-. Esto permite preguntarse si la construcción social de dicho acontecimiento es la búsqueda de una instancia mediadora por medio de la actualización de un imaginario, ante el cual las iniciativas de los actores comprometidos experimentan diversas variaciones propias de los procesos de conversión, adhesión o pertenencia, en calidad de indicadores y modos de gestión de una triple redistribución de la relación al tiempo, al espacio y a la autoridad; de una triple crisis que afecta la identidad, la mediación y la centralidad; y de un triple desajuste: déficit de lo político, explosión o inadecuación de las ofertas de sentido, fuerte disminución y retracción de lo creíble.
\end{abstract}

\begin{abstract}
THE PAPER PRESENTS THE “LAST APPARITIONS OF THE VIRGIN IN LATIN AMERICA” AS AN example of a larger process of "recompositions of the believing in modernity", from the ethnographic reconstruction of an event observed in four contexts: Pereira-Colombia-, Cuenca-Ecuador-, San Nicolas-Argentina-, and Betania - Venezuela-. That explicitation permits to wonder if the social reconstruction of such an event is anything but the search of a mediator instance through the setting of an imaginary in front of which the various initiatives of many actors experiment the huge variations adopted by the processes of conversion, adherence or belonging, as indicators and ways of conduct of a triple re-dispatching of the relation to time, to space and to authority; of a triple crisis that affects identity, mediation and centrality; of a triple lack of adjustment: shortage of the politic, explosion of the offers of sense, strong lacking of the credible.
\end{abstract}

Revista Colombiana de Antropología

Volumen 37, enero-diciembre 200I, pp. 60-89 


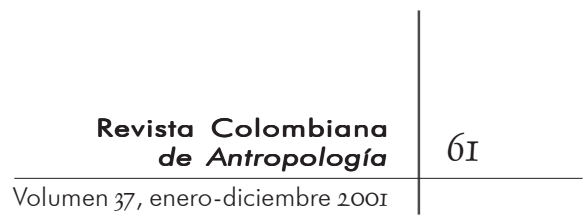

\begin{abstract}
Le 'simulacre' contemporain, c'est en somme la localisation dernière du croire dans le voir, c'est le vu identifié à ce qui doit être cru -une fois abandonné l'hypothèse qui voulait que les eaux d'un océan invisible (le Réel) viennent hanter les rivages du visible et en faire les effets, les signes décryptables ou les reflets trompeurs de sa présence ${ }^{I}$.
\end{abstract}

(Michel de CerTeau, Linvention du quotidien I, "Manières de croire... Chap. XIII: Crédibilités politiques", París, Gallimard, I990: 272-273).

\title{
INTRODUCCIÓN: \\ EL PROBLEMA DEL CREER EN EL MUNDO CONTEMPORÁNEO ${ }^{2}$
}

E

N LAS ÚLTIMAS DOS DÉCADAS, EL SURgimiento de "nuevos movimientos sociales" -especialmente religiosos o políticos- a escala planetaria, estudiados como grupos "neo-comunitarios" que planteaban reivindicaciones tendientes a generar "recomposiciones identitarias"3 -introduciendo una suerte de laicidad que cuestionaba las maneras tradicionales del ejercicio del poder por medio de la irrupción relativamente autónoma del sujeto social, la racionalización de la normatividad institucional, y la instrumentalización de nuevas lógicas de participación-4 ${ }^{4}$, produjo una cierta ampliación en el análisis de las "conversiones sociales" - a partir de sus contenidos ideológicos-en términos generales ${ }^{5}$, y en particular para América latina, exigió la construcción de modelos teóricos capaces de abordar tales dinámicas desde una perspectiva política de
I. "El simulacro contemporáneo es, en suma, la localización última del creer en el ver; es lo visto identificado con lo que debe ser creído - una vez abandonada la hipótesis que deseaba que las aguas de un océano invisible (lo Real), alcanzaran a desbordar los ríos de lo visible produciendo como efectos los signos descifrables o los reflejos engañosos de su presencia" (traducción del autor).

2. Este artículo es una síntesis de la investigación doctoral Les apparitions contemporaines de la Vierge en Amérique latine: un exemple des recompositions du croire au coeur de la modernité, sustentada en l'Ecole des Hautes Etudes en Sciences Sociales de Paris, en diciembre de I999. Las entrevistas citadas en la reconstrucción etnográfica corresponden a transcripciones de los casos considerados en dicha tesis.

3. Michel Wieviorka (I99I) estudió diversos grupos "neocomunitarios", especialmente en Europa del este, distinguiéndolos de los "clásicos movimientos sociales".

4.Danièle Hervieu-Léger (I993: I83) seleccionó esos tres trazos de la modernidad para construir una definición sociológica de la religión en el mundo contemporáneo.

5. En ese sentido, el seminario de Marc Augé y Emmanuel Terray dedicado a la "construcción de una antropología de los mundos contemporáneos" en la Escuela de Altos Estudios en Ciencias Sociales de París, se 


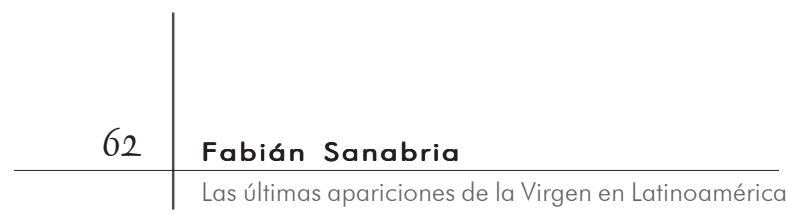

- consagró en los cuatro últimos años al análisis de las lógicas simbólicas productoras y reproductoras de ideologías en contextos aparentemente alejados histórica y geográficamente. Fruto de ese seminario, los últimos libros de M. Augé ilustran ampliamente esas nuevas dinámicas - hoy día confusasen los diversos registros del imagina rio humano a escala global. Cf. Augé, I997 y 2000.

6.Jesús García-Ruiz y Michael Löwy desde hace cinco años construyeron un modelo bastante interesante para analizar fenómenos políticos apoyándose en las ciencias sociales de las religiones, y observar di námicas religiosas utilizando las herramientas de análisis más eficaces de la ciencia política contemporánea. De ello dio testimonio su seminario en el marco de la formación impartida por el Centre d'Etudes Interdisciplinaires des Faits Religieux (CEIFR): "Le religieux, lieu du politique en Amérique latine".

7. Patrick Michel (I997) agregando un nuevo elemento a la teoría antropológica y sociológica de Pierre Bourdieu -"puesta en perspectiva" desde hace cinco años en sus últimas publicaciones y cursos del Colegio de Francia-, demostró cómo es necesario suponer una "matriz común" entre el "campo religioso" y el "campo político", sobre todo a partir de la observación y al análisis de "movimientos comunitarios" que buscan construir "un nuevo sentido del creer".

lo religioso y viceversa ${ }^{6}$. En ese sentido, "lo político de lo religioso y lo religioso de lo político" apareció como un campo de intersección privilegiado para observar las recomposiciones sociales -recomposiciones que ampliaban las "distancias normativas centrales" mostrando la necesidad de pensar un nuevo debate sobre la actualización del creer en nuevos contextos multiculturales y contemporáneos, paralelamente a una comprensión estructural de sus normas lógicas- ${ }^{-}$. Así, la configuración referencial y el análisis discursivo de "itinerarios de conversión" y "trayectorias de identidades" -que constituyen indicadores de un nuevo ordenamiento de las memorias sociales (Halbwachs, I994 [I925])-, empezaba a mostrar un cambio acelerado en los contenidos y referentes que tradicionalmente administraban las representaciones, las creencias y las relaciones sociales. El espacio del creer abarcó entonces los talleres donde un trabajo de re-configuración se efectuaba, la memoria allí se re-componía, la continuidad se reestablecía, el sentido se re-buscaba, y los signos reveladores de afinidades nacientes al lado de un mundo en transformación se multiplicaban (Balandier, 1994: 175).

En efecto, se trataba de pensar un sector central en la comprensión de transformaciones sociales determinantes a corto y mediano plazo, pues si bien era cierto que las "relaciones de producción" explicaban generalmente las lógicas sociales de "amplio alcance" y que tales relaciones estructuraban las formas de dominación de las cuales parecía más difícil librarse (Godelier, I990: I9-4I), no era menos cierto que dimensiones como "lo religioso y lo político" -incluido lo estético- desempeñaban funciones centrales en procesos sociales a mediano y corto plazo. De tal suerte, aproximarnos a las "últimas apariciones de la Virgen en Latinoamérica", en tanto 


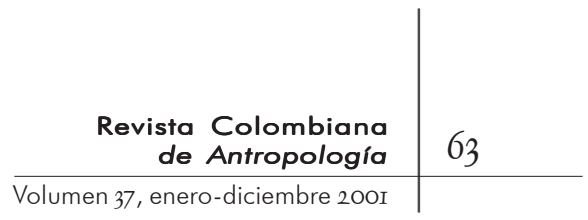

"hecho social total", fue una invitación para reflexionar en torno a la ética del creer en el mundo contemporáneo, prolongando esa perspectiva a partir de una correspondencia lógica con las tendencias epistemológicas aplicadas para analizar dinámicas similares, por medio de la inscripción de ese acontecimiento en un dispositivo evolutivo por el cual el sentido social era recompuesto y afectado $^{8}$. Y tal dispositivo tenía como característica particular que todos sus movimientos presentaban simultáneamente una relación de anticipación y retraso.

De retraso porque el creer, como empresa de construcción de sentido, tiende a frenar el movimiento, inscribiéndolo para traducirlo, en categorías superadas. De anticipación, porque el creer, de igual forma en tanto empresa de construcción de sentido, tiende a orientar el movimiento, para inscribirlo, sea en categorías superadas o en nuevas nociones que él contribuye a inventar (Michel, 1999).

De tal suerte, siguiendo esa perspectiva, el ethos -que significa acto en griego y no costumbre-del latín mores de moraldel creer, sería el conjunto de constantes y variables ajustes efectuados con el fin de gestionar la simultaneidad contradictoria del "orden social", caracterizado por una función de "anticipación y de retraso"; el creer sería entonces el lugar privilegiado de una confrontación, el espacio de una coincidencia. Dicho de otra manera, el creer sería la matriz que permitiría lograr un cierto equilibrio psicosocial en las sociedades, o si se prefiere, el "cam-

8. En última instancia, habría dos posiciones teóricas a partir de las cuales puede aprehenderse el problema del creer en el mundo contemporáneo: la primera se centra en una "interrogación sobre el objeto" -lo dicho, lo enunciado-; la segunda desarrolla específicamente una problemática del "acto de creer" -el decir, la enunciación-. La primera posición pretende reiterar incansable y pasionalmente su cuestionamiento de la veracidad de la creencia, mientras que la segunda busca describir rigurosamente los "modos de circulación de las conciencias creyentes, por medio de objetos susceptibles de expresar y de reunir convicciones". Ambas posiciones - a pesar de su aparente irreconciliación-, pueden ser tendencias complementarias; las categorías son de Michel de Certeau, de una "nota de trabajo" publicada en 1983 , tendiente a "analizar que algunas de las tendencias que adopta la relación de la creencia en la institución" -Certeau en ese momento era profesor en la universidad de California, en San Diego, y buscaba mostrar dos aproximaciones distintas que podían complementarse, según provinieran de la "tradición latina" o de la "corriente anglosajona" con respecto a la creencia-.

9. Quizá parafraseando las Etapas en el camino de la vida de Sören Kierkegaard, el gran desafío del creer en el mundo contemporáneo consista en invertir los términos de estética, ética y religión por estética-o si se prefiere política-, religión y ética. Tal vez ya es hora de ingresar al tiempo del otro "absolutamente otro" que definitivamente no es más Dios (Cf. J. Derrida, 1999). po referencial particularmente estrujado”, en una situación caracterizada por la aceleración en el movimiento de un lado, y por la urgente necesidad de redefinir una nueva relación entre

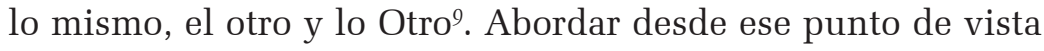


las “últimas apariciones de la Virgen en Latinoamérica”, era también preguntar por la emergencia de una nueva figura de la legitimidad y, más allá de tal surgimiento, por la eficacia creíble de semejante figura.

\section{CONTEXTUALIzACiÓN: HUEllas DE LA VIRGEN TRAS EL ARTE COLONIAL}

$\sum \begin{aligned} & \mathrm{L} \\ & \mathrm{n}\end{aligned}$ L IMAGO ${ }^{\mathrm{IO}}$ DE LA VIRGEN EN AMÉRICA LATINA ES UN FACTOR RELACIOnal que se remonta al "encuentro de dos mundos", fruto de la - experiencia colonial indígena del siglo dieciséis. En efecto, mucho antes de la llegada a América de las principales órdenes religiosas -franciscanos, dominicos y jesuitas-, desde el primer viaje de Colón -quien bautizó a uno de sus navíos con el nombre de la Santa María-, en la mayoría de relatos de los conquistadores, motivados por un fuerte espíritu de cruzada, se constata la tendencia de constituir territorios al fundar ciudades, utilizando variados nombres que evocan las diversas advocaciones de la Virgen. Si bien es cierto que la conquista de América pudo realizarse gracias a la cruz y a la espada, no es menos veraz que la "guerra de las imágenes" hubiese sido, desde el punto de vista ideológico, factor determinante en la colonización indígena. Y en ese proceso de colonización del imaginario de los otros, el papel de la Virgen fue definitivo: en casi todo el continente surgieron incontables leyendas sobre vírgenes conquistadoras, y fueron las comunidades religiosas -justificando o relativizando progresivamente la conquista de América- quienes desarrolla-

IO. Utilizamos esa categoría, que pretende situar el "campo de sentido de la imagen a lo imaginario", desarrollada ampliamente por Jean-Claude Schmitt (I996: 29-37) para el occidente medieval.

II. Es así como Serge Gruzinsky (I990) ve en el culto a la Virgen de Guadalupe una suerte de apropiación o, si se quiere, participación imaginaria "por procuración", en la cual los herederos se dejaron heredar por la herencia. ron un verdadero trabajo pastoral, en el que el imago de la Virgen empezó ser usada para conquistar y colonizar los sistemas simbólicos de representación de la población indígena ${ }^{\mathrm{II}}$.

Mas es en el "campo artístico" donde hay que ver las "vírgenes conquistadoras" de la época colonial. Así, es necesario evocar el estilo barroco, que puede identificarse en diversos momentos del arte como "primacía de lo audaz, lo sorprendente, contrastado e incoherente... producto de 


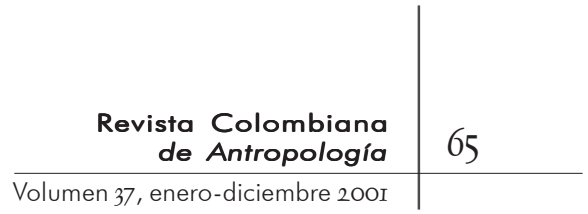

sensibilidades en transición, debido quizás a una cierta remisión de valores tradicionales que hacen surgir tendencias profundas, dolorosas a veces, inquietantes siempre" (Encyclopedia Universalis). Y al recordar la importancia conferida a las imágenes por la Contrarreforma en tanto aspecto sustancial para contrarrestar al protestantismo, hay que subrayar la importancia capital de la iconografía mariana: en todo el mundo católico, y especialmente en América, los altares fueron renovados consagrándose una suerte de "parentela mariana" que abarcó desde la Virgen de Guadalupe cuyo título derivó de la Inmaculada Concepción, pasando por la Virgen de Quito que procede de la Virgen del Apocalipsis, hasta llegar a Nuestra Señora de Chiquinquirá y Nuestra Señora del Topo cuyos iconos se hicieron con el modelo de Pietà del maestro Luis Morales en la Nueva Granada (Fajardo, 1997: 33-40).

Pero de todas las vírgenes conquistadoras, es la Virgen alada o del Apocalipsis quien mejor encarna el síntoma y tal vez la metáfora del arte colonial: el estilo del movimiento y del pliegue ad infinitum y el sentido de lo efímero, del instante eterno evocador de la devoción que pasa por el gozo sensual sublimado y teatralizado. Son en última instancia la construcción de un dispositivo en donde ser es ver hasta perderse en las tinieblas de "tener un ojo para ver lo que se ve" (Buci-Glucksmann, I996). Y esa matriz artística aparecería en cientos de variaciones iconográficas de la América colonial, recreando entre los pliegues del cuerpo de la Inmaculada que culminan aplastando la serpiente y el vuelo de su alma hacia el cielo, una suerte de "caída hacia arriba" que evita todo exceso pasional o convulsión excesiva, señalando tal vez un pasaje para que el "eterno femenino" reaparezca tras las huellas del arte colonial.

\section{La construcción del sentido social en América latina}

T A MEJOR MANERA DE REFERIRSE AL CAMPO RELIGIOSO EN AMÉRICA L latina, es hablar de una matriz común con el espacio de lo político. En efecto, tras una larga confrontación entre la Iglesia y el Estado, luego de la alianza entre "el trono y el altar" ilustrada por tantos historiadores de la época colonial, en los años I93O 
se presentó a lo largo y ancho de Latinoamérica un proceso de globalización o de entrada en modernidad, a partir de lo religioso: del lado católico, más de diecisiete mil misioneros fueron los obreros de semejante empresa, entre los cuales se encontraban religiosos expulsados de China o provenientes de Suiza y Lovaina -que aportaron análisis ligados a la secularización y se comprometieron con el desarrollo social de comunidades urbanas-, y sacerdotes españoles, jesuitas y seculares -que paulatinamente trabajaron en torno a una acción pastoral orientada a la justicia social-; del lado protestante, progresivamente surgieron y se expandieron las comunidades evangélicas -llamadas más tarde pentecostalistas-, que al volverse modernas, con una tendencia cada vez más transdenominacional, difundieron al mismo tiempo una crisis social contra ciertos valores de la modernidad (García-Ruiz, I999). Actualmente, la situación se encuentra en un momento de profunda restructuración, cuya característica fundamental es la consolidación creciente de la desregulación institucional, que se expresa de un lado con la multiplicación geométrica de los pentecostalismos, y de otro con el desarrollo de nuevas formas carismáticas y emocionales que incluyen la pastoral popular y las recomposiciones identitarias en diversos sectores de la Iglesia católica.

Ahora bien, es importante recordar que el catolicismo latinoamericano fue construido históricamente mediante el trabajo de las misiones, las órdenes religiosas y su papel capital en la educación, las parroquias y los movimientos de laicos, etcétera, y que desde la reestructuración de la Iglesia con el Concilio del Vaticano II en los años 1960, surge una preocupación creciente acerca de la cuestión social, especialmente gracias al desarrollo de la Teología de la Liberación y a sus Comunidades Eclesiales de Base (CEB), organizadas local y nacionalmente en varios países latinoamericanos. También es importante subrayar la persistencia de un catolicismo rural que celebra particularmente el culto a las diversas advocaciones de la Virgen y las fiestas de los santos, por medio de procesiones y peregrinaciones que dan sentido a diversas comunidades emocionales, tendientes a vivir una experiencia individual de lo sagrado.

En efecto, ese último catolicismo ha sido reforzado por varios sectores dominantes e innovadores de la Iglesia, jalonando un movimiento llamado Renovación Carismática, en el cual la curación toma lugar prioritario entre otras experiencias religiosas, cuya 


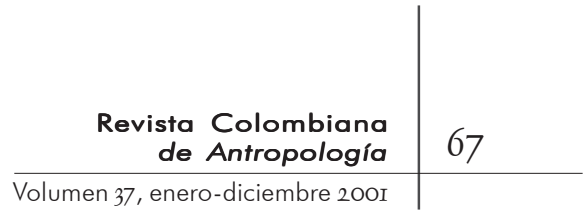

base social la constituyen algunos notables y gente de estratos populares. También hay un crecimiento de la disidencia evangélica: se trata de grupos cristianos que se reconocen en la tradición protestante y que hacen de la lectura de la Biblia, de los dones del Espíritu Santo, de la vida comunitaria, y de la relación directa con lo sagrado, el fundamento de su carisma. Estos grupos crecen y se desarrollan especialmente entre personas de sectores medios y populares de las ciudades latinoamericanas, quienes, tras abandonar la Iglesia católica, dicen haber escogido una nueva manera de creer (Malimaci, I996).

La acumulación económica en los grupos mencionados se hace por medio de diversas estrategias que permiten la circulación de bienes o dinero, y socialmente mediante la creación de empleos y redes solidarias. Así, las estrategias pueden variar según los grupos: mientras la caridad con los pobres es central en el mensaje católico y existe la posibilidad de obtener empleo mediante la extensión geográfica de la oferta a los miembros de las CEB, los pentecostalistas subrayan la prosperidad individual creando nuevas oportunidades de trabajo para sus propios líderes. En general, la acumulación de capital político se logra gracias a la participación en movimientos sociales o según el grado de inserción en un partido dominante o de oposición, y en cuanto a la "economía de bienes simbólicos" (Bourdieu, I994: 177-213), hay diversas estrategias que generan valores, normas, motivaciones y oportunidades que permiten un crecimiento individual y colectivo mediante la recomposición del poder y de la autoestima (Bastian, 1994).

Pero existen diferencias sociales según las expectativas de los miembros de los grupos pentecostalistas y de las CEB, por ejemplo. Conscientes de que toda categorización ideal-típica es simplemente operativa, puede afirmarse que en las CEB hay grupos económicamente pobres pero con una cierta estabilidad profesional, sentimental o familiar, mientras que la mayoría de miembros de los grupos pentecostalistas en el momento de su conversión están vulnerables o angustiados, sin empleo o en estado de precariedad laboral, con problemas de alcoholismo y drogadicción, o en el mundo de la delincuencia. Así, las expectativas son diversas: en las CEB es posible buscar y consolidar espacios comunitarios en busca de mejores condiciones de vida; en los grupos pentecostalistas la prioridad será salir de la vulnerabilidad hasta alcanzar 
una situación de curación individual a fin de recomponer la visión del mundo. Mientras que en las CEB se busca lograr una lectura política y secular de la Biblia con el ánimo de transformar las estructuras del sistema de dominación, en los grupos pentecostalistas hay una tentativa de encontrar a un Jesús liberador, a pesar de que últimamente se presenta una tendencia de modernización del comportamiento religioso, fruto de un proceso de racionalización que implica la adopción de una ética cotidiana y una cierta "sistematización del creer" (Löwy, I996).

Todos esos trazos nos permiten contextualizar una modernidad religiosa en movimiento, que nos obliga a plantear la pregunta de una transición hacia un creer en relativo y a rechazar la tesis de una aparente renovación religiosa, con el ánimo de dotarnos de instrumentos suficientes para poder dar cuenta de las dinámicas contemporáneas de circulación del creer, en términos de diversos itinerarios de sentido, en donde existe la posibilidad de que un grupo pueda "en un contexto de pulverización de la memoria, reconocerse como perteneciente a una línea creyente que él debe prolongar en el futuro" (Hervieu-Léger, I993: I87). Tal es, pues, la contextualización histórica del acontecimiento social de las "últimas apariciones de la Virgen en América latina", del cual hemos seleccionado un contexto referencial -Pereira, Colombia-, y tres contextos restantes -Cuenca, Ecuador, San Nicolás, Argentina y Betania, Venezuela-, debido al respaldo oficial que han tenido de parte de la institución eclesiástica, pues esto nos permitirá averiguar hasta qué punto esas nuevas utilizaciones de signos son capaces de reencontrar de otra forma su función tradicional de determinar el sentido de las cosas. Si esa actualización es una discontinuidad, si se separa del pasado por una desnivelación fundamental de las situaciones, si las respuestas dadas por un lenguaje religioso se han vuelto increíbles, si la relación con el otro es hoy, como ayer, esencial a la constitución del sujeto individual o colectivo, si los relatos que surgen hablan sin la creencia que los expresaba (Certeau, I980: 244). 


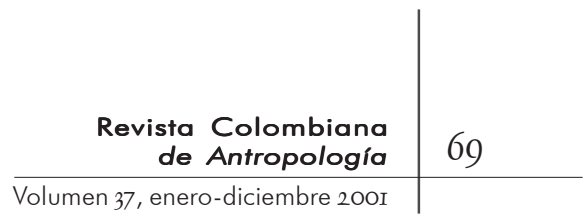

\section{RECONSTRUCCIÓN ETNOGRÁFICA: EL RECUERDO DE UN ACONTECIMIENTO}

\lceil ODO ESTABA DisPuesto PARA QUE LLEGARA A PEREIRA LA MAÑana DEL 25 de enero de I992, cuando una inexplicable procesión de vehículos me detuvo durante horas en la carretera obligándome a abandonar ese propósito. Al darme cuenta que el tiempo transcurría y la situación no mejoraba, decidí abandonar el autobús que me transportaba y caminar cuanto fuera necesario con tal de saber lo que ocurría. Atravesé cientos de carros, buses y camiones preguntando a toda clase de personas que nunca supe si me respondieron, así anduve hasta que un muchachito me explicó lo que pasaba: la Virgen se estaba apareciendo en el jardín que se le había construido. Al escuchar semejante respuesta, sin poder creerla, solté una carcajada. No obstante, el jovencito me invitó a conocer el "Paraíso de María".

Abriéndonos paso entre la multitud logramos abandonar la ruta principal hasta encontrar un caminito polvoriento que nos condujo a una especie de laberinto que atravesamos saltando entre los peregrinos que estaban amontonados en los escalones demarcados por catorce cruces de madera que indicaban las respectivas estaciones del Viacrucis, y al fondo divisamos un campo colmado de personas que se arrojaban al suelo pidiendo perdón por sus pecados al tiempo que trataban de enfocar mejor sus cámaras fotográficas para captar los reflejos del sol que, según muchos, danzaba. El anunciado jardín tenía la forma de un triángulo surcado por una malla metálica a cuyos lados había trece banderas izadas que según mi guía representaban algunos de los países donde recientemente se ha aparecido la Virgen: cinco países latinoamericanos, cinco europeos, Estados Unidos y dos países restantes. Al fondo del triángulo se destacaba una roca construida con pequeñas piedras amontonadas, enmarcada por un arco ligado a una barra rectangular que tiene la silueta de algunos pecesillos metálicos, sobre la cual había dos imágenes: la del Corazón Inmaculado de María y, un poco más alta, la del Corazón de Jesús junto a una cruz de concreto. En el centro hay un altar consagrado para la celebración de la misa, y a los lados se percibían dos sectores claramente definidos: uno de ellos con una cruz de madera suficientemente alta como para crucificar a un hombre, el otro repleto de flores y veladoras que aportaban regularmente los peregrinos. Junto al altar estaba arrodillada una muchacha cuyo 
rostro se dirigía al firmamento, con las manos a la altura del pecho y las yemas de los dedos enfrentadas unas contra otras en señal de oración, que hablaba de espaldas a la multitud utilizando un tono de voz terriblemente agudo mientras la gente se recogía para escuchar lo que su eco repetía, y más tarde ella callaba, y los asistentes lloraban tomando más fotografías hasta que la noche nos envolvía, y de pronto el viento empezó a mover las ramas de los árboles como si la tierra temblara, y todas las personas empezaron a agitar pañuelos blancos y a mover sus manos al cielo en señal de despedida, entonces comprendí que algo terminaba, y decidí quedarme sin imaginar cuánto tiempo a fin de reconstruir lo que en ese momento presenciaba.

Conseguí hospedarme durante seis meses en la casa de mi guía, cuya humilde familia la integraban su madre y dos hermanos que se declaraban "convertidos gracias a las apariciones de María”, a fin de identificar algunas de las condiciones sociales del fenómeno ocurrido y entrevistar desde allí a las personas más cercanas al acontecimiento, hasta reconstruir poco a poco todo un universo de actores y prácticas que me condujo a investigar tres dinámicas similares en otros contextos latinoamericanos.

Las personas que primero entrevisté me respondían lo mismo, era como si conocieran de memoria una versión oficial de lo que había acontecido, una lección que impartían a los demás sobre todo para convencerse a sí mismos. Me decían que todo comenzó el último día de las brujas cuando la joven Luz Elena V. comentó a su madre Fabiola haber tenido una extraña experiencia en la mañana mientras se dirigía en un bus urbano a su colegio: una señora se sentó a su lado y llamándola por el nombre le hizo varias preguntas dándole a entender que sabía dónde vivía y que conocía a su mamá; posteriormente entraron en un diálogo en el cual la señora le hizo recomendaciones acerca de no usar minifalda ni ropas inmodestas, advirtiéndole que cuando se bajara del bus encontraría una imagen y que si esa imagen la impresionaba ésa sería Ella. Me decían que Luz Elena se bajó del bus impresionada, elevada, anonadada, que al entrar al colegio miraba alrededor porque tenía la impresión de que alguien la observaba, de pronto se fijó en la entrada donde tradicionalmente había una imagen de la Virgen descubriendo que la mirada provenía de allí, al acercarse recordó todo lo que le había pasado, se postró de rodillas ante esa imagen, rezó tres avemarías y brotaron algunas lágrimas de sus ojos. Después me contaron que durante los dos 


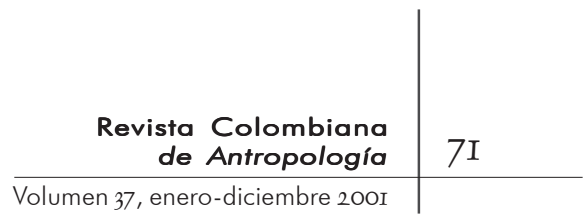

miércoles siguientes, Luz Elena volvió a tener la misma visión en su casa, junto al lavadero, y a principios de noviembre varias personas, inicialmente algunos niños, afirmaron que también habían visto la imagen de la Virgen en los ojos de Luz Elena, lo cual obligó a los familiares de la vidente a construir un altar en su casa y a transformar sin querer la modesta residencia en una especie de centro mariano, o como tantas veces me dijeron, "en un santuario para que la Madre del Cielo nos siguiera acompañando, hasta que le construyeran el jardín que Ella misma pediría para permanecer más tiempo entre los pereiranos" (entrevistas del caso pereirano).

Al dialogar con las personas más cercanas a lo sucedido, aseguraban ser de las que habían visto el reflejo de la Virgen en los ojos de Luz Elena, de forma muy similar a la imagen de la Virgen de la Medalla Milagrosa ${ }^{12}$. Allí descubrí que las personas que decían haber visto ese reflejo en los ojos de la vidente constituían un grupo importante de actores sociales: los miembros de la junta administradora de las apariciones de la Virgen.

-Y, ¿cómo se organizó esa junta?

I2. La Virgen de la Medalla Milagrosa era la imagen que había a la entrada del colegio de Luz-Elena. Su devoción fue bastante difundida en Sudamérica por medio de la orden de las Hermanas Vicentinas. En Pereira llegó a ser tan importante como la Patrona, Nuestra Señora de la Pobreza, y su representación iconográfica guarda una estrecha relación con la nueva advocación de la Virgen de Pereira.

un grupo de personas, y luego de una vigilia de veintidós horas, seleccionó a once para que conformáramos una junta encargada de todo lo referente a su aparición.

En efecto, once personas, casi todas reconocidas y prestantes de Pereira, integraban la junta que sin ánimo de lucro, aún organiza, coordina y difunde todo lo referente al complejo proceso de apariciones marianas ocurridas en esa ciudad.

-Y, ¿cómo continuó todo ese proceso de apariciones?

-Teresita G. -uno de los miembros de la junta administradora de las apariciones de la Virgen-, que viajaba continuamente a Quito, Ecuador, en busca de libros para difundir los mensajes que ha dado María en sus innumerables apariciones, visitó a Luz Elena poco antes de partir de nuevo, porque muy cerca de Cuenca también nuestra Madre del Cielo estaba dando mensajes. Entonces, nuestra vidente le agradeció su visita, contándole que 
desde hacía varios días la Virgen le había pedido que fuera a otro sitio donde también se estuviera apareciendo simultáneamente. Así, en menos de tres horas improvisaron una peregrinación que llegó el 9 de febrero de I99I a la región de El Cajas, cerca a Cuenca, donde encontraron una multitud dispuesta a iniciar el rezo del angelus. Durante su estadía en Cuenca, LuzElena se entrevistó con la vidente de ese lugar y, aunque al principio hubo reticencias, luego fue amablemente acogida.

De modo que Luz Elena debió conocer todo un conjunto de detalles de las apariciones de Cuenca que posteriormente aplicaría en Pereira, y pese a las aclaraciones de algunos de los miembros de la junta pereirana concernientes al hecho de que mientras Luz Elena permaneció en Ecuador, "Ella no conoció ni tuvo acceso a información alguna relativa a lo que era un éxtasis, ni a los mensajes transmitidos por la vidente en ese estado", son evidentes las redundancias que, de todas maneras, reflejó el caso pereirano.

-Al cabo de los mesesitos empezamos a pedir a la Santísima Virgen que se comunicara como lo hacía en Cuenca, porque queríamos tener una experiencia tan maravillosa como la de allá. Queríamos escuchar su voz, que hablara por medio de la vidente; porque ella tenía las alocuciones pero nosotros no nos beneficiábamos directamente, sino que se nos comunicaba después; y tan bella, nos regaló esa gracia y muchas otras más, porque no en todas las apariciones así ha sido.

Me encontraba, pues, ante una segunda fase de las apariciones de la Virgen, fundada en el estado de éxtasis que alcanzaba la vidente, en el que adoptando una posición de rodillas de manera que su columna vertebral alcanzaba a formar un ángulo mayor de $45^{\circ}$ con respecto al plano vertical, y utilizando una voz muy suave, de tono extremadamente agudo y de manera bastante pausada, se dirigía a los peregrinos en nombre de la Virgen.

-En términos generales, ¿̇cuál fue el contenido principal de los mensajes en éxtasis, y cuál la frecuencia de éstos?

-En sus mensajes, la Virgen se dirigía a los peregrinos llamándonos de diversas maneras: hijos, hijitos, pequeños, o aún bebés. En ellos nos impartía, recordaba o reforzaba de manera muy especial algunas de las enseñanzas más sobresalientes del magisterio de la Iglesia católica, haciendo un llamado continuo a la 


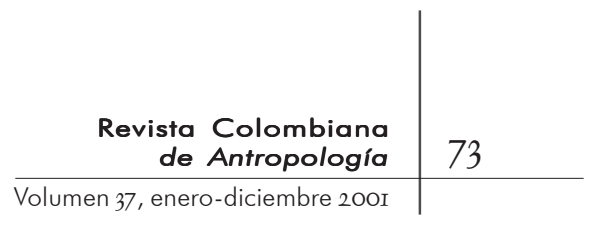

conversión y al cambio de vida. Así mismo, además de ofrecer algunas instrucciones y recomendaciones particulares, hacía un llamado a la práctica de hábitos que condujeran a la oración tales como el rezo del santo rosario con sus quince santos misterios conocidos como el Salterio; al ayuno a pan y agua como signo de penitencia, sacrificio y mortificación; al uso del escapulario y de la camándula al cuello; a la misa, a la comunión y a las visitas diarias a Jesús Sacramentado y confesándonos siquiera una vez al mes; al uso de ropas adecuadas evitando ponerse las niñas minifaldas o los muchachos pantalonetas o pantalones estrechos, sin olvidar las mujeres ponerse una mantilla cada vez que ingresen al templo en señal de respeto al Padre Celestial. De igual forma, la Santísima Virgen nos recomendó la invocación permanente al Espíritu Santo, a los santos ángeles custodios, a los santos arcángeles san Miguel, san Gabriel y san Rafael, a fin de que Ella pueda protegernos bajo su manto para no permitir que Satanás reine en el mundo ni dejar que la música rock y las prendas excitantes que rechazan a Dios se apoderen de sus criaturas más preciadas, es decir, de los jóvenes. Todos sus mensajes fueron constantes, desde marzo de I99I hasta enero de I992, salvo en junio y julio en que fueron un poco más escasos, y aunque buena parte de ellos la Virgen los señaló con día y hora respectivos, hubo muchos otros que se dieron en el momento menos esperado.

-Y, ¿cómo evolucionó el fenómeno de las apariciones de la Virgen en Pereira?

-Ante todo, la Virgen definió su nombre o advocación en esta nueva aparición como "María, llave espiritual de la fe", porque nadie llega a Dios Padre si no es por El Hijo y nadie llega al Hijo si no es por Ella. Nosotros para recordarla mejor, acudimos a una pintora conocida de dos de los miembros de la junta, quien ya había realizado retratos hablados de la Santísima Virgen en otras de sus muchas apariciones, hasta que por fin tuvimos un cuadro aproximado de la nueva advocación de Nuestra Señora. Más tarde, Ella misma nos pidió que se le construyera un jardín como en sus tres últimas apariciones en América: Cuenca, Ecuador, San Nicolás, Argentina y Betania, Venezuela, para que sus hijos pudieran sentirse más cerca de Ella, en un lugar de mayor oración y reconciliación. Así fue como encontramos un terreno con un arroyito de agua en el kilómetro diez de la vía PereiraArmenia, perteneciente a la vereda de El Jordán, que fue donado 


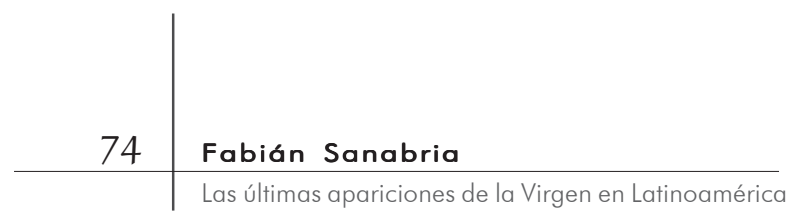

por su propietario al enterarse de nuestro propósito, con tal de que bautizáramos el jardín de la Virgen con el nombre de "El Jordán, Paraíso de María”.

-Y mucha gente acudía al "Paraíso de María"?

-Delegaciones enteras de gente de otras ciudades venían entusiasmadas al Jardín de la Virgen. Al principio venía mucha gente de Manizales y de Bogotá: abogados, médicos, profesionales,

I3. Hay que subrayar el hecho de que gracias a la movilización de actores foráneos, el Jardín de la Virgen empieza a ser eficaz para los actores locales.

I4. Efectivamente, el sol se transformaba en un aro que giraba sobre su eje despidiendo colores que iban desde el azul hasta el rojo, permitiendo contemplarlo sin lastimar los ojos. Dicho fenómeno depende de la cantidad de agua presente en las nubes que en un momento dado se interpone entre el sol y el ojo que lo mira.

I5. Una de las claves para comprender el fenómeno de las "apariciones de la Virgen" consistirá en desarrollar una metáfora a partir del papel que en estas construcciones sociales cumple la fotografía. Por ahora es importante anotar que todos mis informantes para demostrar la veracidad del hecho me mostraban fotografías que ellos calificaban de "milagrosas". En realidad, eran fotografías técnicamente mal tomadas debido a faltas mínimas en el ejercicio de tomar una fotografía. Sin embargo, para ellos era el medio de "dar testimonio a los demás", esperando que otros creyeran lo que ellos ya habían creído.

I6. De acuerdo con el área ocupada por los peregrinos -cerca de Io.000 $\mathrm{m}^{2}-$, puede afirmarse que al último mensaje de "María, llave espiritual de la fe", acudieron cerca de cien mil personas. eso era por lo alto. Gente humilde casi no se venía; eso se notaba especialmente en la gente de Manizales, porque a esa gente se le nota el porte y eso es indiscutible $^{\mathrm{r3}}$. Ahora es cuando ve uno a la gente humilde, al campesinito y a personas de la vereda que comienzan a ir al Jardín, pero eso sí, todo se va saneando y se va desterrando a Satanás.

-Algunas personas insistieron en "reflejos luminosos" ocurridos en el jardín. ¿Cómo era eso?

-Toda esa multitud de personas que cada ocho días venía al Jardín de Nuestra Señora, se sentía atraída sobre todo por el fenómeno de la danza del sol que al principio se opacaba y luego se destapaba, empezando a rebotar como un balón que se lanza y vuelve hasta que uno ya no lo resiste $^{\text {I4 }}$. Entonces la gente comenzaba a tomar fotografías, a llorar de arrepentimiento y a gritar "la Virgen, la Virgen", hasta que por fin la veíamos ${ }^{15}$.

-Y, ¿qué era lo que pasaba el 25 de enero de 1992 cuando por primera vez conocí el Jardín de la Virgen?

-Ese era el último mensaje de Nuestra Señora, y gracias a Dios acudió el mayor número de personas jamás visto en el Jardín ${ }^{\mathrm{I} 6}$. En ese mensaje, María nos motivó a seguir practicando las instrucciones que hasta ese momento nos había dado, aclarándonos que si bien el Padre Celestial le 


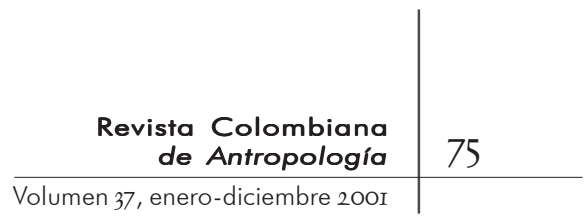

pedía su retirada física de Pereira, Ella seguiría presente en su Jardín, especialmente todos los miércoles a medio día y los últimos sábados de cada mes para recibir las tristezas, alegrías, dolores y esperanzas de sus hijos, y derramar gracias y bendiciones abundantes sobre todos y cada uno de sus peregrinos.

\section{Los actores y sus prácticas sociales}

$\mathrm{H}$ ASTA ESE MOMENTO CONTABA CON UN BUEN NÚMERO DE TESTIMOnios que si bien me situaba ante el proceso de "apariciones marianas de Pereira”, desafortunadamente me impedía comprender a los actores e interpretar las dinámicas sociales que allí se desarrollaron. De manera que tuve que esquivar las explicaciones de mis informantes que trataban de justificar a toda costa la veracidad del fenómeno ocurrido, aunque sentía la imposibilidad de escapar completamente a sus discursos. En consecuencia, empecé a definir cinco tipos de actores que ya había identificado, y traté de caracterizarlos mejor.

El primer tipo de actores lo conformaban la vidente y sus familiares, incluyendo allí a un personaje que estaba en todo sin estar y controlaba todo sin notarse: el director espiritual de Luz Elena. Se trataba de un franciscano renovado, procedente de Calabria, Italia, que vivía en las afueras de Pereira en medio de la pobreza austera de una comunidad de autosubsistencia que en compañía de otros doce frailes construía con materiales regalados: el lugar era tan desprovisto que más que convento parecía tugurio, pero era limpio y agradable, había cabras y cabritos, gallinas y perros guardianes. La presencia de fray Carmelo desconcertaba pues parecía un ser traído del medioevo por la máquina del tiempo, con el hábito tosco, sus largas y ralas barbas de chivo, los pies descalzos en contacto con la tierra, la tonsura radical de la que sólo se salvaba un aro de pelo, y el don de hablar con naturalidad de lo sobrenatural. Lo único que me dijo cuando traté de entrevistarlo fue sencillamente que prefería no hablar del asunto pues bien sabía cuán difícil era de creer, que me invitaba sin embargo a comprobar cómo decenas de familias separadas se reunían, muchos viejos descreídos se confesaban y cientos de jóvenes abandonaban la droga. Aquel religioso fue el único representante de la Iglesia que creyó a Luz Elena cuando 
ella buscaba un sacerdote para confesarle que en el bus se le había aparecido el hada madrina, que sabía todo de ella, que qué haría si de veras era la Virgen como le decía su mamá. Y desde entonces, desde que fue a verlo por primera vez, a pesar de que ella estaba un poco asustada, se convirtió sin más motivos y como por arte de magia en su inseparable padre espiritual.

Luz Elena me pareció una muchacha sencilla y alegre, proveniente de una familia humilde integrada por sus padres, dos hermanos menores y su abuela materna. A pesar de haber recibido una educación católica, aseguraba no distinguirse por su piedad antes de haber visto a la Virgen, aunque la preocupaban, me lo repitió varias veces, "los ritos satánicos que practicaban algunos jóvenes del barrio convocándose a través del rock a todo volumen para reunirse a meter marihuana y después fervorizarse entre ellos, sobre todo los de la esquina que por allá no hay ni que asomarse, es mejor mantenerse a distancia portando el escapulario al cuello pues si no uno se labra su propia condena practicando tanto sexo". Comprobé que la vidente se sometió a los exámenes psicológicos solicitados por el obispo de la diócesis poco antes de que su santidad lo ordenara arzobispo de otra ciudad importante de Colombia para probarlo a ver si su verdadero ministerio estaba en el Vaticano ${ }^{17}$. El diagnóstico clínico advertía un peligro de esquizofrenia a causa de los contenidos representados en éxtasis, especialmente por contar a los doctores sus visiones dantescas del infierno, por describir las

I7. Me refiero a monseñor Darío Castrillón, hoy presidente de la Congregación para el Clero. fervorizaban hasta desarrollarse en ellas"; en fin, la última noticia que supe de Luz Elena fue que ingresó a un convento de monjas de clausura presionada por familiares y amigos, por las damas voluntarias de la Llave Espiritual de la Fe, por su director espiritual, por los rockeros de su barrio que al cabo de tres años componían villancicos navideños, "por los distinguidos monseñores de la Conferencia Episcopal Colombiana cuyo presidente sudaba grasa cada vez que dictaba instrucciones pastorales al pueblo de Colombia, por la Sagrada Congregación del Rito para que los cardenales de Roma le pararan bolas al asunto, por las almas de Santa Teresita y Santa Bernardita sufrientes, por la tradición de los Santos Padres de la Iglesia, por la historia universal, por la salvación del mundo y de los hombres impíos" (Ibídem). 


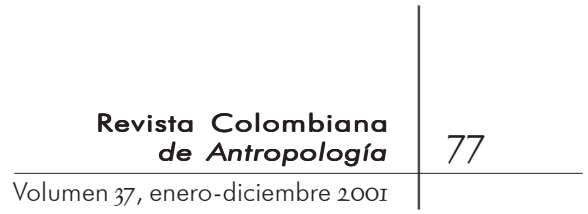

El segundo tipo de actores lo constituían los miembros de la junta administradora de las apariciones marianas de Pereira, de cuyos doce integrantes logré entrevistar a todos excepto a la presidenta, como le decían, una dama de la clase alta pereirana, doña Gladys del Opus, “y la elegimos a ella pa'que no digan qu'ibamos a ser negocio con esto", ella, que me dijo "tan pispo entrevistándonos, pero lo malo es que ahora no puedo responderte porque me deja el avión de Miami, si de algo te sirve decíme dónde te firmo, dónde testifico que me curé de un cáncer en el seno visitando el Paraíso de María... por eso acepté que la Virgen me postulara en su junta, porque hay que agradecérselo, además Ella es muy buena y hay que pedirle la paz para Colombia”. Los demás miembros de la junta eran líderes de la alta y pequeña burguesía pereirana entre los cuales estaban primero Teresita G. -quien compraba y vendía toda clase de libros de apariciones-, después los esposos Lizcano -economistas que mandaban a su único hijo "a estudiar donde los gringos para librarlo de ser arrabalero"-, luego los antioqueños Giraldo -tesoreros de la junta y propietarios de doce plantaciones de café-, más tarde los profesores Trejos -carismáticos publicistas del fenómeno-, y no podían faltar las hermanitas Duque con su exótica tienda de uniformes militares -"para que los jóvenes pereiranos aprendan a vestirse como machos y por ningún motivo se vuelvan roscones"-, ah, y por supuesto hay que nombrar a los industriales Jaramillo - propietarios de papeles de Antioquia "desde hace cinco años arrepentidos de haber sido mormones y vendido a menos precio nuestras fincas cafeteras por culpa de las revelaciones del profeta"-, y por último, la viuda millonaria Adela M. que no sabía qué hacer con sus hijos descarriados hasta que a cada uno de ellos se le fue apareciendo la Virgen.

Los otros actores - del tercero al cuarto, olvidando mejor al quinto tipo, como solía decir a mis colegas--, eran los peregrinos locales, creyentes en las apariciones - entre los cuales había que incluir al pelao que fuera mi principal guía en semejante aventura-, los peregrinos foráneos provenientes de otras ciudades de Colombia y de países vecinos, y la población variable dividida entre espectadores, curiosos, visitantes esporádicos, paseantes de ocasión y espías de todas las profesiones que por ser hombres de poca fe no merecemos ser mencionados. Buena parte de los peregrinos locales y extranjeros eran de estrato popular y clase media -socioeconómicamente hablando- cuyas familias 
se caracterizaban por la ausencia de la figura paterna y un fuerte papel materno en su estructura interna -lo cual permitió con ayuda de la Virgen la conversión de los hijos y el retorno del padre a los hogares al tiempo que todos se sentían bastante preocupados por la descomposición moral de la sociedad y horrorizados con la idea del juicio final y del Apocalipsis-. En cuanto a los últimos actores, simplemente es preferible ignorarlos pues considero que una intención poco ortodoxa nos condujo a aproximarnos a los creyentes, a encararlos e indagar en sus secretos, olvidando que sus testimonios mientras más veraces eran más simples, porque entre más simples tenían que ser más comunes, y entre más comunes parecían tanto más vulgares, y entre más vulgares se acercaban a ser más naturales pues así suele ocultarse según los místicos la sabiduría divina.

Después de caracterizar a los actores, identifiqué tres instituciones que alteraban bruscamente las prácticas sociales de las personas relacionadas con lo sucedido. Concretamente la familia, la Iglesia y la comunidad. Primero, mis entrevistados aseguraron un fortalecimiento de los lazos de solidaridad en sus familias gracias al liderazgo de las madres, quienes en la mayoría de los casos fueron las difusoras de la noticia de las apariciones de la Virgen mostrando a sus hijos buena parte de las fotografías que espontáneamente ellas habían tomado "para dar testimonio de semejante milagro", y así, se instituyó el rezo obligatorio del rosario en los hogares y se renovó el altar familiar con las paredes repletas de imágenes de santos y advocaciones marianas de todas las especialidades en las cuales se volvió a depositar la fe como resolutoria de las necesidades.

-Nuestras mamás se preocuparon de que sus hijos no volvieran a usar tangas ni pantalonetas estrechas, nos colgaron el escapulario en el tobillo y la camándula al pecho, nos cosieron calzoncillos para guardarnos puros hasta el día de nuestro santo matrimonio; a las jovencitas les bordaron faldas largas y enaguas, les tejieron mantillas para que se presenten al templo cubiertas por respeto al Santísimo Sacramento, y nos prohibieron a todos salir de noche a las discotecas y a los lugares donde Dios mío, nuestros ancestros, por quienes doña Adela M. aún no ha acabado de pagar misas, pasaban los fines de semana sinvergüenciando con mujeres de mala vida y el Ángel de la Guarda nos ampare si alguna vez no se desordenaron entre ellos. 


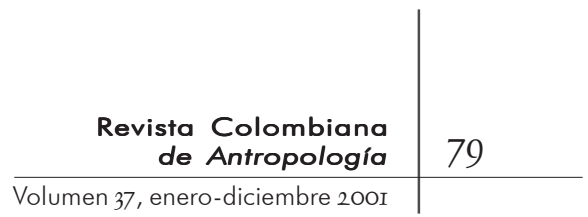

Segundo, el fenómeno ocurrido planteó un serio reto a las jerarquías eclesiásticas, pues los fieles estaban trasladando el culto del domingo en la catedral al sábado en el potrero.

-Entonces Monseñor no pudo apresurarse a desvirtuar ni a prohibir la liturgia en ese lugar, iimagínese!, tuvo que nombrar más bien una comisión de expertos para que estudiara el caso con toda seriedad, y llamó a medianoche a los párrocos para que expresáramos nuestra prudencia por medio de sermones y avisos aclaratorios que básicamente dijeran que "sólo los señores obispos después de una minuciosa investigación de los acontecimientos eran los únicos autorizados para dar aprobación canónica a las apariciones y mensajes de origen sobrenatural”, subrayando que la aprobación episcopal fundamentalmente significaba el acuerdo de esas revelaciones con la recta doctrina de la fe y las buenas costumbres, además de autorizar el culto público y las peregrinaciones oficiales a los lugares reconocidos.

Tercero, la comunidad de Pereira no había respondido suficientemente a la difusión que se había hecho de tamaño acontecimiento por todos los medios de comunicación masiva hasta que el Jardín de la Virgen empezó a convertirse en un parque turístico donde una multitud de gente extraña acudía sin razón cada ocho días. Entonces varias voces quisieron hablar.

Habló el gobernador por la cadena uno y el alcalde por la cadena dos, pero nadie sintonizó esas intervenciones porque en la Señal Colombia Bernardo Hoyos estaba entrevistando al Mago Blanco, ifigúrese!, era una entrevista en vivo y en directo desde la piscina del hotel Rialto en la que el señor De la Cuesta mostraba al país su colección de títulos académicos declarando que en Pereira había un trastorno parasicológico grave, que toda la culpa era del Brujo Negro y sus satánicos, que ya no pueden pervertir más a los futbolistas con pensamientos sucios, que ya las misas negras del papa negro no funcionan porque los jesuitas modernizaron los ejercicios ignacianos, que apenas las sombras del demonio pueden colarse entre los sueños con una amarga nostalgia de la juventud, de ese momento tan triste de la condición humana en el que se queman los últimos cartuchos, y ahí fue cuando el director general de la policía interrumpió el programa de su vida para pedir al doctor una declaración de sólo quince minutos, porque habían descubierto varios centros satánicos donde adultos corrompidos reclutaban jóvenes sicarios 
sirviéndose de la droga y de toda clase de perversiones sexuales para iniciar pelaos en las oscuras sendas de la delincuencia.

\section{Otros contextos considerados}

$\mathrm{F}$

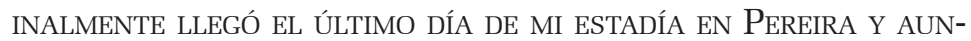
que quise renunciar tuve que continuar mi expedición mariana. Conocí a una familia de Bogotá que como tantas otras cumplía la promesa de viajar a los cuatro principales santuarios de apariciones simultáneas de la Virgen en Sudamérica: a Pereira, Colombia, Cuenca, Ecuador, San Nicolás, Argentina y Betania, Venezuela. En realidad, se trataba de un paquete turístico organizado por el joven Felipe Gómez -estudiante de una universidad privada de Colombia-, quien también aseguraba ver de un momento a otro a la Virgen y reunía todos los jueves para rezar el rosario en su casa a una centena de los mejores ejemplares de niños y niñas bien de la capital que se cogían de la mano y se rozaban las piernas durante las letanías para sentirse en comunión fraterna. Gracias a esa familia integrada por el papá profesional, la madre ama de casa y el tocayo del apóstol, logré aproximarme durante tres meses más a tres nuevos jardines marianos, camuflando mi mirada escéptica entre hermanos ecuatorianos, argentinos y venezolanos.

Al llegar a Quito visité -entusiasmado por la insistencia de mis nuevos guías- la famosa librería espiritual donde Teresita G. compraba sus libros y descubrí una industria editorial formidable de textos y folletos que circulaban por todos los santuarios marianos no sólo difundiendo las últimas apariciones de la Virgen sino también las numerosas vidas de santos y beatos estigmatizados con las llagas de la pasión de Cristo, los secretos de decenas de videntes y mensajeros de ultratumba que han escrito algunas de las claves del fin del mundo, las confesiones de cientos de poseídos por el demonio a quienes se les han practicado exorcismos salvándolos del tormento de ver todos los días el infierno, en fin, los innumerables milagros extraños como el Santo Sudario de Turín o la sangre coagulada en Lanciano incluidas las incontables imágenes que sudan aceite y otras sustancias no identificadas en el vasto mundo de la religiosidad popular donde también se han aparecido miles de vírgenes morenas. 


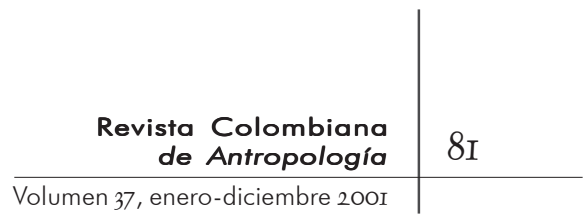

Posteriormente nos desplazamos hacia Cuenca en donde empecé a recolectar diversas versiones sobre esas "nuevas apariciones de la Virgen”, descubriendo que allí el movimiento mariano había involucrado especialmente a personas de origen rural que sin embargo pertenecían a familias de clase media -en términos socioeconómicos-, un tanto desarticuladas por la pérdida de ciertos valores tradicionales cuyos hijos estaban destinados, como sus padres, a ser pequeños comerciantes o tal vez a formarse para ejercer profesiones liberales y, en efecto, la vidente del lugar era una joven de aquellas que prematuramente reciben el don de dominar varias lenguas, tenía veinte años de edad y acababa de terminar el bachillerato, se llamaba Patricia Talbot y era otra de las elegidas de la Santísima Virgen.

Me contaron que todo comenzó a raíz de un sueño que tuvo esa joven el 5 de agosto de I990, cuando una dama alta y blanca de ojos claros y cabellos rubios le indicaba una incomprensible misión.

Al despertar vio una luz inmensa y en medio del resplandor descubrió a la Madre del Cielo que la invitaba a darse un tour por Ciudad de México para que la pudiera ver nuevamente en la basílica de Guadalupe. Entonces Patricia se despertó y muy de mañana arregló maletas para cumplir la cita a Nuestra Señora, empeñó el anillo del novio que seis meses antes la había comprometido y al cabo de diez horas de ayuno llegó acezando a la basílica donde encontró a la Virgen cansada de esperarla todo el día, le pidió que la perdonara por llegar tarde pero es que ella era sólo una pobre mortal que desafortunadamente no contaba con el don de la ubicuidad, que había una huelga en el transporte público y hasta que el sol se ocultó no pudo conseguir un taxi, que el taxista le mandó un recadito a Su Merced suplicándole que la huelga se acabe "pos si no no podemos trabajar con tanto trancón". "Mire, otra vez otro hijo de la chingada, usted misma se da cuenta cómo los cuates nos salpican el barro de las botas saltando por encima de los capotes, pero ahí la dejo pos ya llegamos", y la Virgen la miraba con cara de lástima, más luego le dijo: "No te preocupes mija que con este paro se convierten los incrédulos, además el mensaje que aquí te doy es para los ecuatorianos, anotá el nombre como en tu tierra quiero llamarme Guardiana de la Fe, sí, porque ustedes no tienen quien los cuide, y váyase ya mijita porque a estas horas usted por aquí corre muchos peligros" (entrevistas del caso ecuatoriano). 


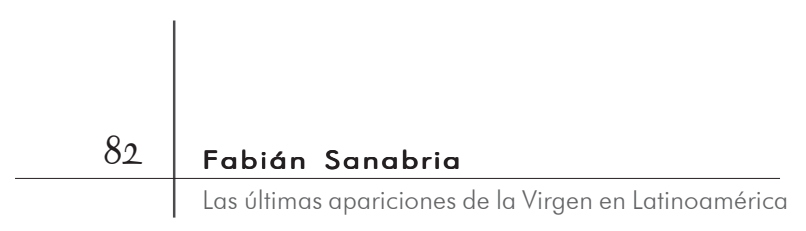

Según siguieron contándome, Patricia llegó a Quito en el último vuelo procedente de México, y encontró sentado en el aeropuerto despoblado a un sacerdote flaco y encorvado, el rector de la universidad de los jesuitas, el padre Julio Terán, que desde aquella noche desvelada se convirtió en su inseparable consejero. Tiempo después, la vidente ecuatoriana convocó un rosario en un lugar desierto llamado El Cajas -sobre la ruta inacabada que descendía a la costa- al que asistieron más de cinco mil personas que días más tarde construirían en ese sitio un jardín como el de Pereira, claro que de forma rectangular para hacerlo más funcional, bueno, "y ahí también hubo una espectacular aparición de la Virgen en presencia de casi medio millón de espectadores el último veinticinco, como entre los pereiranos, igualito, como en el Sermón de la Montaña antecitos de la multiplicación de los panes y los peces”. Paralelamente identifiqué los mismos actores y prácticas sociales que en Pereira, sólo que en Cuenca "algunos jovencitos no quisieron convertirse tan rápido prefiriendo antes que eso quebrar las estatuas veneradas en el jardín de su Guardiana, pero gracias a Dios las autoridades civiles tomaron cartas en el asunto y eso ayudó a que el señor obispo aprobara con más gana las peregrinaciones, en fin, afortunadamente el peligro ya pasó y todavía siguen viniendo como usted ve, multitud de peregrinos que hasta el día de la Inmaculada acudirán para presenciar la consagración del nuevo templo. Hace seis meses que Patricia se despidió de la Virgen contando con el divino permiso de su Hijo para entregarse a su impaciente prometido y salvarlo, icómo le parece!, la semana pasada anunciaron su explosión de felicidad pues el Todopoderoso los premió con trillizos" (loc. cit.).

Un mes después viajamos a San Nicolás, a más de doscientos kilómetros de Buenos Aires, donde ya había un templo erguido en honor a la Virgen del Campito, teniendo que esperar hasta el domingo en la misa de las doce para ver comulgar a la vidente, una señora de medio siglo, doña Gladys de Mota, la abuela de los peladitos más lindos que cantaban en el coro, la escogida de la Virgen en aquel sitio. También allí habían acudido miles de personas de todo el mundo, y hubo casi los mismos fenómenos que en las dos anteriores apariciones, con danza del sol y miles de fotografías desenfocadas, excepto que en esta manifestación mariana el obispo de la diócesis era el mismo director espiritual de la vidente y la mayoría de peregrinos eran ex trabajadores de la Sociedad Siderúrgica Mixta Argentina, la principal acería del 


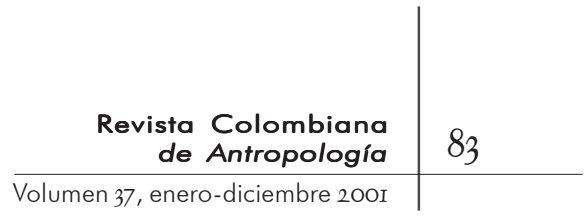

país gaucho que había adoptado años atrás una aplastante política de privatización y racionalización cuyo impacto en la población local incrementó el desempleo determinando la caída del consumo y el deterioro de las actividades económicas así como el debilitamiento de la trama social a escala de la ciudad (entrevistas del caso argentino).

Por último, pasamos varios fines de semana en la finca de Betania en la provincia de Cúa del estado de Miranda en Venezuela, donde siempre nos invitó a tomar chocolate una abuela de origen italiano, doña Esperanza de Bianchini, quien allí era la vidente de la Santísima Virgen "Reconciliadora de los Pueblos", en cuyo honor existía muy cerca una basílica y un centro de atención pastoral. Aunque las indagaciones que pude realizar sobre esas últimas manifestaciones marianas fueron escasas pues la población visitante del lugar era demasiado móvil, algunos jóvenes -cuyas familias han seguido supuestamente el desarrollo del fenómeno a lo largo de casi una década- me sugirieron dos aspectos relevantes para imaginar a los actores de esa dinámica: en primer lugar una doble función de monseñor, quien -como el obispo de San Nicolás- era el director espiritual de la vidente y la autoridad de la Iglesia encargada de determinar la veracidad de lo ocurrido y, en segundo lugar, la referencia a un conflicto que desde hacía varios años se libraba entre ciertas familias por causa de las tierras donde se realizaban las apariciones, sin duda alguna las más fértiles de la región (entrevistas del caso venezolano).

En ese punto me despedí de mis anfitriones marianos, del señor y la señora Gómez; agradeciéndoles su hospitalidad durante las peregrinaciones, envié con ellos un cinturón de cuero que varias veces había seducido a mi guía de Pereira, disculpándome por no haberlo abrazado cuando partí para Quito; mandé estampas de las otras vírgenes a todos mis amigos marianos, a las damas voluntarias de la Llave Espiritual de la Fe, a los pelaos rockeros, en fin, a tantas y tantos que conmigo compartieron. Felipe me acompañó al aeropuerto un tanto triste porque todavía no me había convertido, porque aún no me había entregado completamente al Altísimo, porque no había seguido más adentro en la espesura hasta gustar el mosto de granadas y descender al pozo donde mana el agua pura; entonces le pedí que me encomendara al Todopoderoso en sus oraciones para que muy pronto pudiera volver al Paraíso de María y someterme por fin a los ardores del 
Ferventísimo, que mientras tanto debía viajar a Bogotá y seguir estudiando con rigor el fenómeno de las apariciones marianas. En el último instante el tocayo del apóstol se aferró a mi cuello, lloró y me dio un beso de despedida argumentando que la Virgen lo permitía pues para eso Cristo nos había vuelto hermanos, que al fin y al cabo qué importaba, que me quería con el fervor más puro de un amigo. Tras dos horas de siesta en un vuelo atocigado, desperté en el dorado aeropuerto de la capital de Colombia donde con gran alegría me recibieron familiares y amigos. Desde entonces el tiempo pareciera ser un espejo empolvado y, ahora, he escrito estas líneas que en alguna medida recrean ese acontecimiento.

\section{EXPLORACIÓN HERMENÉUTICA: \\ APOCALÍPTICAS MILENARISTAS \\ Y SOCIODISEAS DE LA ESPERANZA}

I OS CUATRO CASOS CONSIDERADOS DE "LAS ÚlTIMAS APARICIONES $\perp$ de la Virgen en Latinoamérica" constituyen un acontecimiento que, si bien puede inscribirse en la "nebulosa místicoesotérica" estudiada por Françoise Champion (I989: I55-I69) al caracterizar los nuevos movimientos religiosos de las sociedades posmodernas como delirios, nos obliga a subrayar que dichos delirios no sólo estaban bien fundados, sino que movilizaron: de un momento a otro, pareciera como si la guerra de las imágenes propia de la época colonial se transformara en guerra de sueños correspondiente a la situación contemporánea; es decir, como si una realidad destituida se transformara en situación restituyente -las ciudades consideradas, todas ellas con población inferior a quinientos mil habitantes, fueron consagradas a una advocación de la Virgen en el momento de su fundación, y es posible establecer una relación iconográfica directa o inversamente proporcional entre las nuevas advocaciones marianas y las vírgenes fundadoras de los contextos considerados-. Entonces nos corresponde preguntarnos si acaso nuestro sujeto de estudio no convocaba tres funciones vitales del orden social: la memoria -como revitalización del pasado-, la conciencia -en tanto idealización del presente- y la imaginación -como representación del futuro-. 


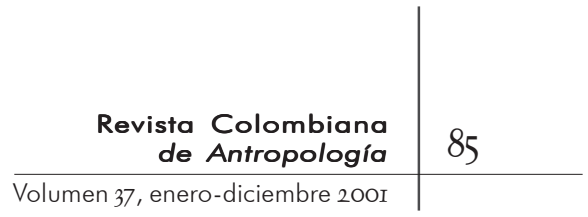

En ese orden de ideas, una sociología de la esperanza se impone, y tres funciones reguladoras del equilibrio psicosocial trabajarían conjuntamente para formar y recomponer lo que Durkheim llamó en Las formas elementales de la vida religiosa "lo sagrado": "en la conciencia colectiva se fomenta el surgimiento o, si se quiere, la surrección de los dioses; en la memoria, su resurrección o al menos su resistencia a la muerte; y en la imaginación, algo que va de par con una insurrección" (Desroche, I973: 2IO). Así, las apocalípticas milenaristas presentes en las "últimas apariciones de la Virgen", manifiestas en los diagnósticos tenebrosos por parte de los actores al caracterizar su realidad social, participaban de la expresión global de una actualidad: esas dinámicas constituyen un acontecimiento religioso en el que estalla una sociedad, y un acontecimiento social en el que estalla una religión -en Pereira había una confrontación armada entre los dos carteles de la droga al igual que los más altos índices de delincuencia juvenil de Colombia; en Cuenca, una confrontación de valores morales entre dos generaciones; en San Nicolás, una situación de extrema pobreza y desempleo producida por la privatización de la principal acería de Argentina; y en Betania, un conflicto entre dos familias por las tierras donde se realizaban las "apariciones de la Virgen", que son las más prósperas de la región-.

Ahora bien, todo proceso de imaginación colectiva es, ante todo, una demanda ética ${ }^{\mathrm{I}}$ : una petición que denuncia la destitución de un recuerdo, solicitando la restitución de un olvido. "Porque la imaginación conduce a la insurrección de los dioses, ella reencuentra en su estallido tanto la conciencia como la memoria colectivas (...) A la conciencia le ofrece una representación, a manera de un cuasi culto de posesión (...) a la memoria le recrea su propia referencia a una tradición, validando el proyecto de un después por medio del recuerdo de un antes" (Desroche, 1973:

I8. Esta expresión ha sido tomada de la noción de transferencia desarrollada por Lacan en I973: "Dar lo que no se tiene al que no lo quiere" 225). De tal suerte, las apocalípticas milenaristas de nuestro sujeto de estudio nos conducen a mirar de otra manera su teatro vivido, el escenario donde tal vez se desarrollaba una sociodisea de la esperanza, quizá el anhelo de una manera de ser a la vez uno y otro. ¿Una nueva identidad en otra alteridad?

De una cierta manera, todo pudo ocurrir como si en la experiencia de la aparición, en la puesta en acto de ese simulacro 
que no es menos cierto por parecer un montaje colectivo o la ficción alucinante de un grupo, el encuentro con otros que veían lo mismo o algo similar superara las diferencias. Obviamente el problema surgía cuando una visión hegemónica pretendía imponerse a las demás. No obstante, las diversas escalas de imaginación o de visión, si se reconocían, podían ser complementarias, es decir armoniosas; la dificultad mayor se concentraba en el exceso o en el defecto de imaginación -el uno siendo alienante, el otro escéptico-. En todo caso, en los actores directamente involucrados, tres funciones debieron cumplirse: la experiencia extraña de un secreto inconfesable, la exploración de la posibilidad de ser uno confrontado a la necesidad de convertirse en otro, y finalmente, un convencimiento transformado en dramatización, en operación teatral.

Mas es necesario evocar aquí el epígrafe de la Sociología de la esperanza de Henri Desroche, en el cual Gershom Shölem nos recuerda que "vivir de la esperanza es grandioso pero al mismo tiempo profundamente irreal"; y sin embargo, reconocer que esa realidad no impidió al autor de semejante sociología escribir un Diccionario de los mesianismos y milenarismos de la era cristiana, en el cual debía haber varias páginas en blanco para ser completadas en el futuro, porque "Perpetuamente hombres de dios hacen dioses de hombres y dioses de hombres hacen hombres de dios y, en el sumum de esa recreación, los hombres se vuelven hombres y los dioses se transforman en dioses" (Desroche, I969). Y en una de las páginas blancas de ese diccionario real, nuestra labor no puede menos que escribir una redundancia poética: culminando su segundo milenio la cristiana era / Cinco siglos ya de evangelización de las Américas / En diversos lugares de tal mundo legendario / Imágenes del eterno femenino reaparecen.

\section{Creencias metonímicas y metonimias del creer}

T AS MANERAS DE CREER QUE HEMOS DESCRITO Y TRATADO DE INTERL pretar presentan en su reconstrucción discursiva el deseo de afirmar un decir, de suerte que al contar su propio relato, su propia retórica especulativa contienen lo que Wittgenstein (I965: 3I3) llamaba "juegos de lenguaje”, especialmente al describir cómo 


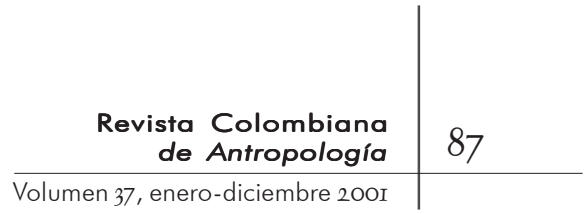

"la gramática del creer va de la mano con la proposición que se cree"; o como lo afirmara Michel de Certeau (I980: 280): "la debilidad de un decir sólo implica la pérdida constituyente de un creer". En alguna medida, los relatos que combinamos para este estudio, implican un decir no diciendo o la función metonímica de llamar una cosa por otra. Parece ser que nuestro ejemplo de "recomposiciones del creer en el corazón de la modernidad" cumple también el último requisito del dispositivo enunciado por Patrick Michel (1999) para construir una "antropología del creer en el mundo contemporáneo": hablando de lo ocurrido, se finge hablar de eso pues, se habla en realidad de otra cosa; y no hablando de lo ocurrido, se finge no hablar de eso, no hablando sino de eso.

Y tanto peregrinos como convertidos, paseantes como adherentes de la circulación del creer que hemos reconstruido a partir de los cuatro casos considerados de las "últimas apariciones de la Virgen en Latinoamérica", al escribir su propio relato para dar testimonio de su creencia compartida, nos corroboran lo que Danièle Hervieu-Léger (I999: I77-200) ha llamado "validación carismática del creer", en el sentido de que, típicamente, para las videntes y los administradores del acontecimiento "la institución autoriza y califica la conformidad", mas al observar los "peregrinos locales", es "la comunidad quien determina la coherencia”, y al desplazarnos a los peregrinos foráneos "es el otro quien señala la autenticidad"; cabría preguntar si "los actores de poca fe” certificamos que algo inefable se dijo. 


\section{Bibliografía}

Augé, Marc. 1997. La guerre des rêves. Seuil. París.

— Fictions fin de siècle. 2000. Seuil. París.

Balandier, George. 1994. Le dédale. Pour en finir avec le XXème siècle. Fayard. París.

Bastian, Jean-Pierre. I994. Le protestantisme en Amérique latine. Une approche socio-historique. Labor et Fides. Ginebra.

Bourdieu, Pierre. 1994. Raisons pratiques, Seuil. París. 1997. Méditations pascaliennes. Seuil. París.

Buci-Glucksmann, C. 1996. La folie de voir. De l'estétique baroque, Gallimard. París.

Certeau, Michel de. 1980. La faiblesse de croire. Seuil. París. - 1983. "L'institution du croire". En Le Magistère. Recherches de science religieuse. $\mathrm{N}^{\mathrm{a}}$ spécial. París.

- I9go. L'Invention du quotidien I. Gallimard. París.

ChAmpion, Françoise. "Les sociologues de la postmodernité et la nébuleuse mystique-ésotérique". En Archives de Sciences Sociales des Religions 67. EHESS. París.

Derrida, Jacques. 1999. Donner la mort. Galilée. París.

Desroche, Henri. I969. Dieux d'hommes. Dictionaire des messianismes et milénarismes de l'ère chrétienne. Mouton. París-La Haya. I973. Sociologie de l'espérance. Calman-Lévy. París.

Fajardo, Martha. 1997. "El espíritu barroco en el arte colonial". En Figuras de éxtasis en el arte colonial. Presidencia de la República. Bogotá.

García-Ruiz, Jesús. 1999. "Pentecostales y neo-pentecostales en Guatemala: ideología social, escatología, espacio político y redes sociales”. En Estudios y Documentos I4: 49-105. Guatemala.

Godelier, Maurice. I990. "Transformations de la nature et rapports sociaux”. En Les rapports sociaux et leurs enjeux. Vol. II. IRSC. París.

GruZinsky, Serge. I99o. La guerre des images. De Christophe Colomb à "Blade Runner". Fayard. París.

Halbwachs, Maurice. I994 [1925]. Les cadres sociaux de la mémoire. Albin Michel. París.

Hervieu-LÉGer, Danièle. 1993. La religion pour mémoire. Cerf. París. 


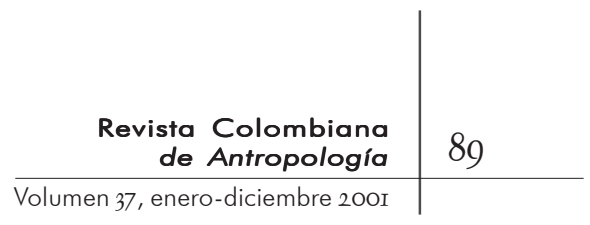

1999. Le pélerin et le converti. La religion en mouvement. Flammarion. París.

LACAN, JACQUES. Les quatre concepts fondamentaux de la psycanalyse. Seuil. París.

Löwy, Michel. 1996. The War of Gods. Religion and politics in Latin América. Verso. Londres.

Malimaci, Fortunato. I996. "Demandas sociales emergentes: pobreza y búsqueda de sentido. Redes solidarias, grupos religiosos y organismos no-gubernamentales". En Desempleo estructural, pobreza y precariedad. Coordenadas y estrategias de política social en América latina. CEUR. Buenos Aires.

Michel, Patrick. 1997. Religion et démocratie. Nouveaux enjeux, nouvelles approches. Albin Michel. París.

_ . 1999. "Nation, religion, pluralisme: une réflexion fin de siècle". En Critique internationale 3: 3-30. París.

SANABRIA, FABIÁN. 1999. Les apparitions contemporaines de la Vierge en Amérique latine: un exemple des recompositions du croire au coeur de la modernité. Ecole des Hautes Etudes en Sciences Sociales. París (tesis doctoral no publicada, sustentada por el autor de este artículo).

Schmitt, Jean-Claude. I996. "Imago: de l'image à l'imaginaire”. En L'image (vol 5). Fonctions et usages des images dans l'Occident médiéval. París.

Wieviorka, Michel. "Nature et formation des mouvements communautaires". En Modernisation et mobilisation sociale. CEDEJ. París.

Wittgenstein, Ludvig. 1965. De la certitude. Gallimard. París.

ZAmbrano, Vladimir. I993. Hombres de páramo y montaña. ICAN. Bogotá. Bogotá. 